\title{
In vitro biosynthesis of UDP-N,N'-diacetylbacillosamine by enzymes of the Campylobacter jejuni general protein glycosylation system
}

\author{
Nelson B. Olivier $\ddagger$, Mark M. Chen $\ddagger$, Jonathan R. Behr§, and Barbara Imperiali ${ }^{\ddagger}{ }^{*}$ \\ $\$$ Departments of Chemistry and Biology, Massachusetts Institute of Technology, 77 Massachusetts Avenue, \\ Cambridge, Massachusetts 02139 \\ $\S$ Division of Biological Engineering, Massachusetts Institute of Technology, 77 Massachusetts Avenue, \\ Cambridge, Massachusetts 02139
}

\begin{abstract}
In Campylobacter jejuni the sugar 2,4-diacetamido-2,4,6-trideoxy- $\alpha$-D-glucopyranose, termed N,N '-diacetylbacillosamine (Bac2,4diNAc), is the first carbohydrate in the glycoprotein $\mathrm{N}$-linked heptasaccharide. Starting with uridine diphosphate-N-acetylglucosamine (UDP-GlcNAc) two enzymes of the general protein glycosylation ( $\mathrm{Pgl}$ ) pathway in C. jejuni (PglF and $\mathrm{PglE}$ ) have been recently shown to modify this sugar nucleotide to form UDP-2-acetamido-4-amino-2,4,6-trideoxy$\alpha$-D-glycopyranose (UDP-4-amino-sugar) [Schoenhofen, I. C., et al. (2006) J Biol Chem 281, 723732]. PglD has been proposed to catalyze the final step in $\mathrm{N}, \mathrm{N}^{\prime}$-diacetylbacillosamine synthesis by $\mathrm{N}$-acetylation of the UDP-4-amino-sugar at the $\mathrm{C} 4$ position. We have cloned, overexpressed and purified PglD from the $p g l$ locus of $C$. jejuni NCTC 11168 and identified it as the acetyltransferase that modifies the UDP-4-amino-sugar to form UDP-N, $\mathrm{N}^{\prime}$-diacetylbacillosamine, utilizing acetyl coenzyme A as the acetyl group donor. The UDP-N, $\mathrm{N}^{\prime}$-diacetylbacillosamine product was purified from the reaction by reverse phase C18 HPLC and the structure determined by NMR analysis. Additionally, the full-length PglF was overexpressed and purified in the presence of detergent as a GST-fusion protein allowing for derivation of kinetic parameters. We found that the UDP-4-aminosugar was readily synthesized from UDP-GlcNAc in a coupled reaction using PglF and PglE. We also demonstrate the in vitro biosynthesis of the complete heptasaccharide lipid-linked donor by coupling the action of eight enzymes (PglF, PglE, PglD, PglC, PglA, PglJ, PglH, and PglI) in the Pgl pathway in a single reaction vessel.
\end{abstract}

Campylobacter jejuni is the Gram-negative enteropathogen identified as the primary cause of gastroenteritis in humans and the most frequent infection to precede the peripheral neuropathy Guillain-Barré syndrome (1-3). Infection of humans generally occurs by ingestion of contaminated livestock or water. Although the mechanism of infection is not clearly understood, production of glycolipids and glycoproteins by the pathogen have been found to influence cell motility, host-cell interactions, and competence for DNA uptake (4-6). As resistance to antimicrobial agents rises, the potential for development of novel therapeutics against enzymes that produce glycoconjugates has intensified efforts targeted at the characterization of their biosynthetic pathways. In C. jejuni four major glycan structures have been identified: lipooligosaccharide (LOS), capsule, O-linked glycan, and N-linked glycan

\footnotetext{
*To whom correspondence should be addressed: Department of Chemistry, Massachusetts Institute of Technology, 77 Massachusetts Ave., Cambridge, MA 02139. E-mail: imper@ mit.edu, (v) 617-253-1838, (f) 617-452-2419.

This material is available free of charge via the Internet at http://pubs.acs.org
} 
(7-10). The genes coding for enzymes that synthesize these glycan moieties have been found in clusters throughout the $C$. jejuni genome. The respective biochemical functions of the gene products have been assigned on the basis of biochemical data or sequence homology to glycosyltransferases and other enzymes known to modify sugars (11-13).

A common $\mathrm{N}$-linked glycan has been detected in at least 22 periplasmic and cell-surface proteins $(14,10)$ in $C$. jejuni, and the Pgl pathway has been identified as the source of its biosynthesis. Genes of the $p g l$ locus in the pathogen have been designated $c j 1119-c j 1130$ and the structure of the N-linked glycan has been shown to be the heptasaccharide GalNAc- $\alpha 1,4-$ GalNAc- $\alpha 1,4-($ Glc $\beta 1,3)-G a l N A c-\alpha 1,4-G a l N A c-\alpha 1,4-G a l N A c-\alpha 1,3-B a c 2,4 d i N A c-\_1-A s n$ where GalNAc, GlcNAc, and Glc represent N-acetylgalactosamine, N-acetylglucosamine, and glucose, respectively, (Figure 1) (10). Assembly of this bacterial glycan begins with pyrophosphate bond formation between the Bac2,4diNAc phosphate and undecaprenylphosphate (Und-P) by Cj1124c (PglC) to form Bac2,4diNAc- $\alpha 1-P P-U n d ~(15)$. One N-acetylgalactosamine (GalNAc) is linked to the polyisoprenepyrophosphate-bound N,N

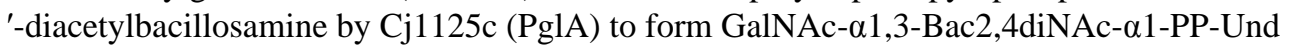
(16). Next, four additional GalNAc and one branching glucose are added sequentially to the isoprene-linked disaccharide by PglJ, PglH, and PglI, to form the heptasaccharide (17). In Nlinked glycoproteins the heptasaccharide is covalently attached at the $\mathrm{N}, \mathrm{N}^{\prime}-$

diacetylbacillosamine through a $\beta$-linkage to the amide nitrogen ( $\mathrm{N}$-linked) of an asparagine side chain in the canonical sequence Asn-Xaa-Ser/Thr motif, where Xaa can be any amino acid except proline (4).

Nearly all enzymes encoded in the $p g l$ locus from $C$. jejuni strain NCTC 11168 responsible for synthesis of the heptasaccharide have been biochemically characterized $(15,17,16,18)$. Recently our laboratory reported biochemical evidence of enzyme-mediated glycosyltransferase activity, which strongly suggested that N,N'-diacetylbacillosamine was initially formed in C. jejuni as a uridine diphosphate derivative (Figure 2) (15). In these experiments a lengthy chemical synthesis was undertaken to produce UDP-Bac2,4diNAc and $\mathrm{PglC}$ was found to transfer Bac2,4diNAc phosphate to the undecaprenylphosphate lipid. The original bacillosamine, or 4-acetamido-2-amino-2,4,6-trideoxy-D-glucose was isolated and identified over thirty years ago from Bacillus licheniformis $(19,20)$. The difference between that bacillosamine and the derivative found in the $C$. jejuni $\mathrm{N}$-linked heptasaccharide is an Nacetyl group at the $\mathrm{C} 2$ position. Figure 1 shows a scheme for the biosynthesis of UDP-N, $\mathrm{N}^{\prime}-$ diacetylbacillosamine in C. jejuni beginning with UDP-GlcNAc. In this model Cj1120c (PgIF) performs a cofactor-dependent hydride transfer from the C4 position of UDP-GlcNAc to C6, in conjunction with the elimination of water across the glucosyl C5 and C6 bond. The mechanism for the reaction is believed to follow a process similar to other C6 dehydratases such as dTDP-D-glucose-4,6-dehydratase (RmlB) from Salmonella enterica (21), resulting in the production of UDP-2-acetamido-2,6-dideoxy- $\alpha$-D-4-ketohexulose (UDP-4-keto-sugar) (18). Cj1121c (PglE) catalyzes the pyridoxal-dependent transfer of an amino group from Lglutamate to the $\mathrm{C} 4$ position of the UDP-4-keto-sugar to form the UDP-4-amino-sugar (18). The final step in the enzymatic synthesis of UDP-Bac2,4diNAc is the proposed $\mathrm{N}$-acetylation at the $\mathrm{C} 4$ position of the UDP-4-amino-sugar by $\mathrm{Cj} 1123 \mathrm{c}$ (PglD).

The native dehydratase PglF has three domains: an N-terminal transmembrane domain, a Cterminal catalytic domain, and a linker between the transmembrane and catalytic domains. Recently, Logan and coworkers identified the biochemical activity of PglF by studying a construct that lacked the transmembrane domain (18). These investigators further reported that enzyme activity could not be detected in a coupled reaction between the truncated form of PglF and full-length PglE, suggesting that the transmembrane domain plays an important role in the coupled enzyme reaction. The truncation approach has also proven advantageous in the functional analysis of WbpM, a homologue of PglF, which is involved in pseudaminic acid 
biosynthesis in P. aeruginosa. In their experiments, Creuzenet and Lam found that the fulllength WbpM retained activity, but only when isolated in the membrane fraction of the host expression system (22).

In this report we detail the functional characterization of PgID in addition to the biosynthesis and purification of UDP-Bac-2,4-diNAc. By harnessing the UDP-Bac2,4diNAc biosynthetic process in vitro we provide a rapid and cost-effective means to produce this rare sugar in milligram quantities. We also characterized the full-length $\mathrm{PglF}$ and demonstrate the in vitro enzymatic synthesis of the undecaprenylpyrophosphate-linked heptasaccharide in a coupled reaction that combined PglF, E, D, C, A, J, H, and I in a single reaction vessel. The results presented herein complete the functional identification of enzymes involved in the biosynthesis of the $N$-linked heptasaccharide in $C$. jejuni.

\section{EXPERIMENTAL PROCEDURES}

\section{Molecular Biology}

Amplification of $p g l$ gene sequences from C. jejuni 11168 genomic DNA (ATCC 700819, designation NCTC 11168) were performed with oligonucleotides described in Table 1. BamH I and Xho I restriction sites were engineered to facilitate cloning of all amplicons into either pGEX4T-2 (GE Healthcare) to incorporate an N-terminal GST tag or pET-24a(+) (Novagen) to incorporate an $\mathrm{N}$-terminal $\mathrm{T} 7$ and a $\mathrm{C}$-terminal hexahistidine tag. Full-length $p g l \mathrm{D}$ and $p g l \mathrm{E}$ were subcloned into the $\mathrm{pET}$ vector. Full-length $p g l \mathrm{~F}$ and a truncated form of $p g l \mathrm{~F}$ coding for residues M130-V590 were subcloned into the pGEX vector to express GST-PglF and GST$\mathrm{PglF}_{130}$, respectively. The full-length GST fusion PglF construct also included a C-terminal octahistidine tag. Amplifications were accomplished with the Stratagene Cloned Pfu Polymerase system as described by the manufacturer. Amplicons were purified and doubledigested with BamH I and Xho I. Digested inserts and linearized vectors were fractionated by agarose gel electrophoresis and purified with the QIAquick Gel Extraction kit (Qiagen). Ligations were conducted with the T4 DNA Ligase kit (Promega) using an overnight incubation at $16^{\circ} \mathrm{C}$. Chemically competent DH5 $\alpha$ strain of $E$. coli (Invitrogen) were transformed with the ligation reactions and colonies selected on Luria Bertani (LB) agar plates supplemented with either kanamycin or carbanicillin. Plasmids from colonies representing each construct were isolated and sequenced at the MIT CCR HHMI Biopolymers Laboratory.

\section{PgID and PglE Expression and Purification}

Chemically competent BL21 (DE3) pLysS strain of E. coli (Invitrogen) were transformed for expression. For each construct $10 \mathrm{~mL}$ of an overnight culture was used to inoculate one liter of LB broth supplemented with $30 \_\mathrm{g} / \mathrm{mL}$ kanamycin and $50 \_\mathrm{g} / \mathrm{mL}$ chloramphenicol for selection, and incubated at $37^{\circ} \mathrm{C}$. At an $\mathrm{OD}_{600}$ of $0.6-1.0$ the cultures were cooled to $16^{\circ} \mathrm{C}$ prior to induction with $0.5 \mathrm{mM}$ isopropyl_-D-1-thiogalactopyranoside (IPTG). After $22 \mathrm{hrs}$ of incubation at $16^{\circ} \mathrm{C}$, the cells were harvested by centrifugation, resuspended in a solution of $0.9 \% \mathrm{NaCl}$ and pelleted for storage at $-80{ }^{\circ} \mathrm{C}$. Pellets of cells that expressed PglD or PglE were resuspended in $50 \mathrm{~mL}$ ice cold lysis buffer $(50 \mathrm{mM}$ Tris-acetate, $100 \mathrm{mM} \mathrm{NaCl}, \mathrm{pH} 7.5)$ supplemented with $30 \mathrm{mM}$ imidazole, lysed by sonication, and lysate cleared by centrifugation at $145,000 \times g$ for 45 minutes at $4{ }^{\circ} \mathrm{C}$. Further handling of protein occurred at $4{ }^{\circ} \mathrm{C}$ unless otherwise stated. Cleared lysate was mixed with $4 \mathrm{~mL}$ Ni-NTA (Qiagen) resin per liter of original culture then tumbled for 4 hours. The Ni-NTA resin-protein mixture was packed into a K 9/15 column (GE Healthcare) and washed with 10 column volumes (cv) of lysis buffer supplemented with $30 \mathrm{mM}$ imidazole at a flow rate of $3 \mathrm{~mL} / \mathrm{min}$. The resin bound protein was further washed with $20 \mathrm{cv}$ of lysis buffer containing $40 \mathrm{mM}$ imidazole then $10 \mathrm{cv}$ of lysis buffer containing $50 \mathrm{mM}$ imidazole. To elute the protein of interest a $30 \mathrm{cv}$ gradient of imidazolelysis 
buffer from $50 \mathrm{mM}$ to $500 \mathrm{mM}$ was applied to the column. Protein concentration was determined using the Micro BCA kit (Pierce).

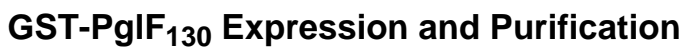

Chemically competent BL21 (DE3) pLysS cells were transformed for expression of the GST$\mathrm{PglF}_{130}$ construct. A $10 \mathrm{~mL}$ volume of an overnight culture was used to inoculate one liter of LB broth and incubated at $37^{\circ} \mathrm{C}$ with $50 \_\mathrm{g} / \mathrm{mL}$ carbanicillin and $50 \_\mathrm{g} / \mathrm{mL}$ chloramphenicol for selection. At an $\mathrm{OD}_{600}$ of $0.6-1.0$ the culture was cooled to $30^{\circ} \mathrm{C}$ then induced with $1 \mathrm{mM}$ IPTG and incubated at $30^{\circ} \mathrm{C}$ for three hours, then harvested and stored at $-80{ }^{\circ} \mathrm{C}$. Frozen cell pellets were resuspended in $50 \mathrm{~mL}$ of ice cold PBS buffer $(140 \mathrm{mM} \mathrm{NaCl}, 2.7 \mathrm{mM} \mathrm{KCl}, 10$ $\mathrm{mM} \mathrm{Na}_{2} \mathrm{HPO}_{4}, 1.8 \mathrm{mM} \mathrm{KH}_{2} \mathrm{PO}_{4}, \mathrm{pH} 7.3$ ), lysed by sonication, and the lysate cleared by centrifugation at $145,000 \times g$ for 45 minutes. To purify, cleared lysate was mixed with $4 \mathrm{~mL}$ of glutathione Sepharose 4 Fast Flow resin (GS) (GE Healthcare) per liter of original culture, and tumbled to mix for 4 hours. The GS resin-protein mixture was packed into a K 9/15 column and washed with $25 \mathrm{cv}$ of PBS at a flow rate of $3 \mathrm{ml} / \mathrm{min}$. Protein was eluted with an isocratic flow of GS elution buffer (50 mM Tris, $10 \mathrm{mM}$ L-glutathione, $\mathrm{pH}$ 8.0). Fractions containing purified material were identified by SDS-PAGE subjected to Coomassie staining or Western blot analysis probing for the affinity tag. Target fractions were pooled and exhaustively dialyzed against PBS. Protein concentration was determined using the Micro BCA kit.

\section{Full-length PgIF Expression and Purification}

A $20 \mathrm{~mL}$ volume of an overnight culture of BL21 (DE3) pLysS cells transformed with the GST-PglF construct was used to inoculate $2 \mathrm{~L}$ of LB broth supplemented with $50 \_\mathrm{g} / \mathrm{mL}$ carbenicillin and $50 \_\mathrm{g} / \mathrm{mL}$ chloramphenicol, and cultured at $37^{\circ} \mathrm{C}$. At an $\mathrm{OD}_{600}$ of $0.6-1.0$, the culture was cooled to $16{ }^{\circ} \mathrm{C}$, induced with $0.5 \mathrm{mM} \mathrm{IPTG}$, and incubated at $16{ }^{\circ} \mathrm{C}$ for 22 hrs. Cells were harvested and frozen at $-80^{\circ} \mathrm{C}$ until required. Frozen cell pellets were thawed in $100 \mathrm{~mL}$ ice cold PBS and lysed by sonication, then supplemented with $200 \mu \mathrm{M} \mathrm{NAD}^{+}$. Cellular debris was cleared by low-speed $(8,000 \times g)$ centrifugation for 45 minutes. The resulting supernatant was transferred to a clean centrifuge tube and subjected to high-speed centrifugation $(145,000 \times g)$ for 45 minutes to pellet the cell envelope fraction. The supernatant was discarded and the resulting pellet homogenized in $10 \mathrm{~mL}$ of PBS supplemented with $1.0 \%$ (v/v) Triton X-100 and $200 \mu \mathrm{M}$ NAD ${ }^{+}(\mathrm{PBS}-\mathrm{T})$. The detergent solution was tumbled at $4{ }^{\circ} \mathrm{C}$ for 2 hours then centrifuged at $145,000 \times g$ for 1 hour. The supernatant containing detergentsolubilized GST-PgIF was carefully removed so as not to disturb the pellet and then combined with $2 \mathrm{~mL}$ of GS resin pre-equilibrated in PBS-T. The GS resin-protein solution was tumbled for 4 hours then poured into a column and the resin was allowed to settle. Using gravity flow the resin-bound protein was washed with $25 \mathrm{cv}$ of PBS-T containing $0.1 \%$ Triton X-100, then eluted with the GS elution buffer supplemented with $0.1 \%$ Triton X-100 and $200 \mu \mathrm{M} \mathrm{NAD}^{+}$. Fractions containing purified material were determined by SDS-PAGE (10\%) subjected to Coomassie staining or Western blot analysis probing for the His-tag. To determine protein concentration a sample of the pooled fractions was exhaustively dialyzed against $0.1 \%$ Triton $\mathrm{X}-100$ PBS-T then assayed with the Micro-BCA kit.

\section{Enzymatic Reactions}

To synthesize UDP-4-keto-sugar with purified GST-PglF, $1.5 \mathrm{mg}(16.1 \mathrm{nmol})$ of enzyme in a $15 \mathrm{~mL}$ solution containing $5 \mathrm{mM}$ L-glutathione, $50 \mathrm{mM}$ Tris-acetate, $0.1 \%$ Triton X-100, 200 $\mu \mathrm{M} \mathrm{NAD}^{+}, 50 \mathrm{mM} \mathrm{NaCl}, 1 \mathrm{mM}(15 \mu \mathrm{mol})$ UDP-GlcNAc, $\mathrm{pH} 8$ was incubated for 10 hours at $28{ }^{\circ} \mathrm{C}$. A sample of the reaction was filtered using a Microcon filtration unit $[10 \mathrm{~K}$ molecular weight cut-off (MWC) - Millipore] for capillary electrophoresis (CE) analysis. A sample of the filtrate was equally mixed with methanol and injected into a Mariner Biospectrometry Workstation under a constant flow of $10 \mu \mathrm{L} / \mathrm{min}$ with data acquisition conducted in negative 
mode. To synthesize the UDP-4-amino-sugar by coupling the reactions of GST-PglF and PglE, the following components were added to a reaction as described above: $5 \mathrm{mg}(108.5 \mathrm{nmol})$ purified PglE, L-glutamate and pyridoxal-5'-phosphate (PLP) to a final concentration of 15 $\mathrm{mM}$ and $100 \mu \mathrm{M}$, respectively, then incubated for 24 hours at $28^{\circ} \mathrm{C}$. The reaction volume was passed through a $10 \mathrm{~K}$ MWC filter then diluted 100 fold with $\mathrm{H}_{2} \mathrm{O}$ and loaded onto a $5 \mathrm{~mL}$ HiTrap Q FF anion exchange column (GE Healthcare) at a flow rate of $3 \mathrm{~mL} / \mathrm{min}$. The bound sugar was washed with $100 \mathrm{~mL}$ of $\mathrm{H}_{2} \mathrm{O}$ and eluted over a $120 \mathrm{~mL}$ gradient from 0 to $220 \mathrm{mM}$ triethylammonium bicarbonate (TEAB), pH 8.6. Fractions containing purified UDP-4-aminosugar were identified by CE then pooled, lyophilized, and analyzed by ESI-MS as described above. The UDP-4-amino-sugar product was quantified spectrophotometrically using the molar extinction coefficient of UDP $\left({ }_{-262}=10,000 \mathrm{M}^{-1} \mathrm{~cm}^{-1}(23)\right)$. Approximately $2.3 \mathrm{mg}$ (3.9_mol) of UDP-4-amino-sugar were recovered from the coupled enzyme reaction. As an alternative to synthesize UDP-4-amino-sugar, approximately $15 \mathrm{mg}$ (190.5 nmol) GST-

PglF 130 was bound to $4 \mathrm{~mL}$ of GS resin. PBS was added to the slurry such that the total volume measured $15 \mathrm{~mL} .20 \mathrm{mg}(33 \mu \mathrm{mol})$ UDP-GlcNAc was added and the reaction incubated at 28 ${ }^{\circ} \mathrm{C}$ overnight. The reaction was resuspended into a slurry, poured into a column, and the flowthrough collected and then filtered with a 10K MWC membrane. In a total volume of $25 \mathrm{~mL}$, the filtrate was combined with $15 \mathrm{mg}(325.5 \mathrm{nmol})$ of purified PglE. L-glutamate and PLP were added to a final concentration of $20 \mathrm{mM}$ and $100 \mu \mathrm{M}$, respectively. The reaction was incubated for 48 hours at $28^{\circ} \mathrm{C}$ and the product purified as described for the coupled reaction. Recovery of UDP-4-amino-sugar by this method was approximately $9.5 \mathrm{mg}$ (16_mol). NMR chemical shifts and coupling constants of this material were virtually identical to published data (18). To synthesize UDP-Bac2,4diNAc enzymatically, in a total volume of $5 \mathrm{~mL}, 5 \mathrm{mg}$ $(212 \mathrm{nmol})$ of PglD was combined with $10 \mathrm{mg}(17.0 \mu \mathrm{mol})$ UDP-4-amino-sugar and $14 \mathrm{mg}$ $(17.3 \mu \mathrm{mol})$ AcCoA (Sigma-Aldrich). The reaction was incubated at $37^{\circ} \mathrm{C}$ for 3 hours then filtered with a $10 \mathrm{~K}$ MWC membrane. The entire filtrate was loaded onto a preparative scale reverse phase C-18 column (Waters YMC Pack-Pro C18, $250 \times 20$ mm I.D., S-5 $\mu \mathrm{m}$ particle size, $12 \mathrm{~nm}$ pore size) equilibrated with $50 \mathrm{mM}$ TEAB, $\mathrm{pH} 7.1$ and eluted with a linear gradient of $0-25 \%$ acetonitrile over $300 \mathrm{~mL}$. Eluting material was monitored for absorbance at $262 \mathrm{~nm}$ and fractions containing pure UDP-Bac2,4diNAc identified by CE. Target fractions were pooled and the solvent concentrated under reduced pressure to yield $6 \mathrm{mg}$ of UDP-

Bac2,4diNAc.

\section{NMR Spectroscopy}

A 4 mg sample of purified UDP-Bac2,4diNAc was resuspended in $600 \mu \mathrm{L}$ of $99 \% \mathrm{D}_{2} \mathrm{O}$ (Cambridge Isotopes) and placed in a 5-mm tube. All data was collected at $25^{\circ} \mathrm{C}$. A solution of $85 \%$ phosphoric acid in $\mathrm{D}_{2} \mathrm{O}$ was used as an external standard for ${ }^{31} \mathrm{P}$ NMR and $\mathrm{D}_{2} \mathrm{O}(4.8$ $\mathrm{ppm})$ as the internal standard for ${ }^{1} \mathrm{H}$ NMR spectrum calibration. The NMR data were processed with the MestRe-C (Mestrelab Research) software package. ${ }^{1} \mathrm{H}$ and COSY spectra were obtained on a Bruker Avance-600 NMR spectrometer equipped with a pulse-field gradient triple resonance probe using standard pulse sequences from Bruker NMR. Homonuclear decoupling spectra were obtained on a Varian Inova-500 NMR spectrometer equipped with a pulse-field gradient triple resonance probe using standard pulse sequences from Varian. ${ }^{31} \mathrm{P}$ spectra were measured with a Varian Mercury 300 NMR spectrometer with a pulse-field autoswitchable probe.

\section{CE Analysis}

CE was performed using a Hewlett Packard 3D CE system with UV detection and manual integration with the HP 3D CE software package. The running buffer was composed of $25 \mathrm{mM}$ sodium tetraborate, $\mathrm{pH} 9.4$ using a bare silica capillary $(75 \mu \mathrm{m} \times 80 \mathrm{~cm})$ with a detector distance of $72 \mathrm{~cm}$. The capillary was conditioned before each run by washing with $0.4 \mathrm{M} \mathrm{NaOH}$ for 2 min, water for $2 \mathrm{~min}$, and running buffer for $2 \mathrm{~min}$. In general each sample was prepared by 
filtration with a $10 \mathrm{~K}$ MWC membrane, then diluted with water by a ratio of 1:4. Samples were introduced by pressure injection for $16 \mathrm{~s}$ at $30 \mathrm{mbar}$ and the separation was performed at 22 $\mathrm{kV}$.

\section{Kinetic Measurements}

For GST-PglF, $1.3 \mu \mathrm{g}$ of enzyme was incubated in a reaction volume of $50 \mu \mathrm{L}$ with $200 \mu \mathrm{M}$ $\mathrm{NAD}^{+}, 0.1 \%$ Triton X-100, $50 \mathrm{mM}$ Tris-acetate, $50 \mathrm{mM} \mathrm{NaCl}, 5 \mathrm{mM}$ L-glutathione, $\mathrm{pH} 7.7$ with UDP-GlcNAc at 6 different concentrations varying from $0.8 \mathrm{mM}$ to $31 \mathrm{mM}$. The reactions were incubated at $37^{\circ} \mathrm{C}$ for $200 \mathrm{~min}$, boiled for $2 \mathrm{~min}$ then filtered through a $10 \mathrm{~K}$ MWC membrane and analyzed by $\mathrm{CE}$ as described above. UDP-4-amino-sugar substrate for the PgID assays was enzymatically synthesized and quantified as described above. For each reaction $0.025 \mathrm{ng}$ of enzyme was incubated in a total volume of $20 \mu \mathrm{L}$ containing $50 \mathrm{mM}$ Tris-acetate, $50 \mathrm{mM} \mathrm{NaCl}, 2 \mathrm{mM}$ AcCoA, $\mathrm{pH} 7.7$ and $5 \mu \mathrm{g}$ bovine serum albumin to serve as a carrier protein with UDP-4-amino-sugar at 6 different concentrations varying from $0.1 \mathrm{mM}$ to $2 \mathrm{mM}$. The reactions were incubated at $37^{\circ} \mathrm{C}$ for $90 \mathrm{~min}$, then boiled and filtered as done for the GSTPglF kinetics reactions.

\section{Radioactive Assay Coupling PgID, C and A using labeled AcCoA}

Und-P was synthesized as described elsewhere (24,25). A $3 \mu \mathrm{L}$ volume of DMSO and $7 \mu \mathrm{L}$ volume of $14.3 \%(\mathrm{v} / \mathrm{v})$ Triton X-100 were added to a tube containing $50 \mathrm{nmol}$ Und-P. After vortexing and sonicating in a water bath, $1 \mu \mathrm{L}$ of $1 \mathrm{M} \mathrm{MgCl}_{2}, 10 \mu \mathrm{L}$ of $10 \mathrm{mM}$ UDP-GalNAc, $15 \mu \mathrm{L}$ of $7 \mathrm{mM}$ UDP-4-amino-sugar, $10 \mu \mathrm{L}$ of PglC at $0.25 \mathrm{mg} / \mathrm{mL}, 10 \mu \mathrm{L}$ of PglA at $0.5 \mathrm{mg} /$ $\mathrm{mL}, 1.5 \mu \mathrm{L}$ of unlabeled $14 \mathrm{mM}$ AcCoA, and $1 \mu \mathrm{L}$ of $20 \mu \mathrm{M}\left[{ }^{3} \mathrm{H}\right]$ AcCoA (American Radiolabeled Chemicals) were added, giving the reaction a specific activity of $48 \mathrm{nCi} / \mathrm{nmol}$. The reaction was initiated by adding $10 \mu \mathrm{L}$ of PglD at $0.5 \mathrm{mg} / \mathrm{mL}$ and incubated at room temperature. Aliquots of $12 \mu \mathrm{L}$ were taken at 2, 4, 8, 30, and $60 \mathrm{~min}$. Reactions were quenched and prepared for liquid scintillation counting as described elsewhere (15).

\section{Heptasaccharide Biosynthesis}

Components of the reaction were assembled in two tubes. Tube one contained Und-P ( $5 \mathrm{nmol})$, UDP-GlcNAc, UDP-GalNAc, and UDP-Glc (each at $1 \mathrm{mM}, 1 \mathrm{mM}$, and $0.2 \mathrm{mM}$ final concentration, respectively) suspended with $3 \mu \mathrm{L}$ of DMSO, and $7 \mu \mathrm{L}$ of $14.3 \%$ Triton X-100 by vigorous vortexing and water bath sonication. Next, $4 \mu \mathrm{L}$ of purified PglC, PglA, PglJ, and $\mathrm{PglH}$ (the latter two at $0.5 \mathrm{mg} / \mathrm{ml}$ stock concentration) were added, along with $10 \mu \mathrm{L}$ of a PgII cell envelope fraction. Each prepared as described elsewhere (17). Combined in tube two were $3 \mu \mathrm{L}$ of $15 \mathrm{mM} \mathrm{NAD}^{+}, 10 \mu \mathrm{L}$ of $200 \mathrm{mM} \mathrm{L}-\mathrm{glu}, 10 \mu \mathrm{L}$ of $2.7 \mathrm{mM}$ PLP, $5 \mu \mathrm{L}$ of $20 \mathrm{mM}$ AcCoA, $10 \mu \mathrm{L}$ of PglD, $25 \mu \mathrm{L}$ of PglE, $37 \mu \mathrm{L}$ GST-PglF $(0.5 \mathrm{mg} / \mathrm{mL}, 0.5 \mathrm{mg} / \mathrm{mL} .0 .15 \mathrm{mg} / \mathrm{mL}$ protein stock concentration, respectively). The reaction was initiated by adding $64 \mu \mathrm{L}$ of tube two to tube one then and then the mixture was incubated at room temperature for seven hours. The heptasaccharide was isolated and analyzed by HPLC and MALDI-MS as described elsewhere (15).

\section{RESULTS}

\section{Cloning, Expression and Purification of PgID, PgIE, and PgIF}

Full-length $p g l D$, pglE and $p g l F$ werecloned from the $C$. jejuni strain NCTC 11168 genomic DNA and expressed in E. coli. Clones coding for PglE and PglD were expressed with an Nterminal T7-tag and a C-terminal His $_{6}$-tag (Table 1). Both constructs overexpressed robustly in $E$. coli and purified by nickel-affinity chromatography with protein yields near $25 \mathrm{mg} / \mathrm{L}$ culture. Full-length PglF was expressed with an N-terminal glutathione S-transferase (GST) domain concurrently with a C-terminal octahistidine tag (GST-PglF). GST-PglF was purified 
in the presence of detergent and $\mathrm{NAD}^{+}$by affinity chromatography with a yield of $1.5 \mathrm{mg} / \mathrm{L}$ culture. Similar to the construct reported by Logan and coworkers (18), we expressed GST$\mathrm{PglF}_{130}$ (M130-V590) which omitted the putative transmembrane domain of full-length PglF. This truncated construct expressed well in E. coli yielding approximately $20 \mathrm{mg} / \mathrm{L}$ culture. Confirmation that purified material represented the target proteins was accomplished by SDSPAGE and Western blot analysis to detect the affinity tags (Figure 3).

\section{Dehydratase activity of GST-PgIF}

The reaction of GST-PglF was analyzed by CE using UV absorbance $(262 \mathrm{~nm})$ to detect the eluting species (Figure 4A). Although consumption of the cofactor was not apparent, catalytic activity by GST-PglF was enhanced in the presence of additional $\mathrm{NAD}^{+}$but not $\mathrm{NADP}^{+}$(data not shown). Electrospray ionization mass spectrometry (ESI-MS) analysis of the GST-PglF reaction indicated a mass of $587.5 \mathrm{Da}$, consistent with the formation of UDP-4-keto-sugar. CE analysis of the same reaction indicated the presence of starting material (data not shown), consistent with the ESI-MS observation of a species having a mass of 605.5 Da (Figure 5A). Alternatively, it is possible for the keto-sugar to exist in equilibrium with the corresponding diol form (26). The diol of the catalytic product of PglF would correspond to the addition of 18 atomic mass units (water) to the UDP-4-keto-sugar. Therefore the mass of 605.5 Da may be attributed, in part, to the diol form of the PglF product.

\section{Acetyltransferase activity of PgID}

PglD is a putative acetyltransferase (6). Amino acid sequence analysis shows the C-terminal domain to be consistent with a hexapeptide repeat motif. Members from a subclass of the hexapeptide repeat enzymes, known as xenobiotic acetyltransferases, have been shown to use acetyl-Coenzyme A (AcCoA) for acetylation of a variety of substrates $(27,28)$. Purified PglD was incubated with the purified UDP-4-amino sugar and AcCoA in excess. The resultant CE elution profile showed two additional peaks that flanked the substrate and cofactor signals (Figure 4B). To confirm that an acetyl group was transferred to UDP-4-amino-sugar, the PgID reaction products were purified by reverse phase high performance liquid chromatography (RP-HPLC) and analyzed by ESI-MS and CE. Consistent with the loss of a proton and addition of an acetyl group to form UDP-Bac2,4diNAc, the ESI-MS revealed a mass peak of 630.5 (Figure 5B). The RP-HPLC purification step also separated a species with an atomic mass of 767, consistent with the Coenzyme A (CoASH) (data not shown).

To further demonstrate acetyl group transfer by PgID to the UDP-4-amino-sugar, a coupled enzyme assay was employed using $\left[{ }^{3} \mathrm{H}\right] \mathrm{AcC}$ AA. Isolation of the labeled UDP-Bac2,4diNAc was simplified by incorporating purified $\mathrm{PglC}$, an integral membrane glycosyltransferase from C. jejuni responsible for transferring Bac2,4diNAc phosphate to the isoprene lipid carrier Und$\mathrm{P}$ (15), into the assay. PlgA, which transfers the first GalNAc onto Bac2,4diNAc-PP-Und (17), was also included to consume the product of $\mathrm{PglC}$, thus driving the reaction forward and facilitating isolation of the labeled product. In addition to cofactors and salts, reactants included purified the UDP-4-amino-sugar, Und-P, and UDP-GalNAc (Figure 6A). The organic phase was extracted and assayed for radioactivity. Because AcCoA was expected to remain in the aqueous layer, counts in the organic layer were attributed to incorporation of a radiolabled acetyl group into the polyisoprenepyrophosphate-linked substrate (Figure 6B). For control reactions, the Und-P or the UDP-4-amino-sugar was omitted. Both control reactions resulted in background levels of counts, strongly suggesting acetyl group transfer to UDP-4-amino by PglD (Figure 6B).

\section{NMR analysis of the PgID product}

To further establish the identity of the enzymatic product of PglD, the proton NMR spectra of the purified PglD reaction product was analyzed. A series of homonuclear decoupling 
experiments was conducted to identify the chemical shifts for protons from the pyranose ring (supporting information, Figure S-1). In the proton spectrum two peaks centered at $2.05 \mathrm{ppm}$ with a total peak area of six protons suggested the presence of two acetyl groups in the compound (Figure 7). In comparison to the observed chemical shift of proton $\mathrm{H}-4$ on the UDP-4-amino-sugar (18), the H-4 apparent triplet shifted to a more de-shielded position of

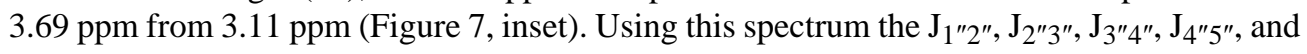
$\mathrm{J}_{5^{\prime \prime}} 6^{\prime \prime}$ coupling constants were measured and are listed in Table 2 . The coupling constant values were essentially identical to published values for the UDP-4-amino-sugar, hence the UDPBac2,4diNAc glucopyranose ring has the same stereochemistry. The ${ }^{31} \mathrm{P}$ spectrum (supplemental information, Figure S-2 and S-3) and chemical shift assignments for uracil and ribose moiety protons (Table 2) matched published values for UDP-sugars $(18,29)$. On the basis of the results presented the product of PglD was identified as UDP-2,4-diacetamido-2,4,6trideoxy- $\alpha$-D-glucopyranose.

\section{Kinetic analysis of PgIF and PgID}

GST-PglF and PglD appeared suitable for analysis by Michaelis-Menten kinetics since the reaction velocities were observed to plateau below $20 \mathrm{mM}$ and $2 \mathrm{mM}$ substrate concentration, respectively, in the presence of $200 \mu \mathrm{M} \mathrm{NAD}^{+}$for GST-PglF and $2 \mathrm{mM} \mathrm{AcCoA}$ for PglD.

Product formation velocities were averaged from two reactions run in parallel for each substrate concentration. Observed values were plotted and kinetic parameters derived with the software SigmaPlot (Systat Software, Inc). Apparent kinetic parameters for GST-PglF were $\mathrm{K}_{\mathrm{m}}=7.0$ $\mathrm{mM} \pm 1.4 \mathrm{mM}, \mathrm{k}_{\text {cat }}=7.1 \pm 0.53 \mathrm{~min}^{-1}$. Apparent kinetic parameters for PglD were $\mathrm{K}_{\mathrm{m}}=0.41$ $\mathrm{mM} \pm 0.078 \mathrm{mM}, \mathrm{k}_{\mathrm{cat}}=4.83 \times 10^{5} \pm 0.30 \times 10^{5} \mathrm{~min}^{-1}$.

\section{Coupled reaction with PgIF, E, D, C, A, J, H, \& I}

We noted inhibition of GST-PglF 130 dehydratase activity on UDP-GlcNAc in the presence of PglE (data not shown). This observation suggested a physical interaction between the distinct enzymes, as reported by Logan and coworkers using a $\mathrm{PglF}_{130}$ construct with a C-terminal His-tag only (18). We coupled the reaction of GST-PglF with PglE and analyzed the products by CE. A peak eluting ahead of the UDP-GlcNAc peak was observed, consistent with the CE migration of the UDP-4-amino sugar (supplementary information, Figure S-4). To confirm the UDP-4-amino sugar was indeed formed in the reaction, GST-PglF and PglE were combined with UDP-GlcNAc, PLP, and L-glu. The reaction mixture was incubated overnight and the reaction product purified by anion exchange chromatography. ESI-MS analysis of the purified material showed a prominent mass peak of 588.5 (Figure 5c). Because PglE specifically uses the UDP-4-keto-sugar as its primary substrate we conclude the product of GST-PglF is indeed the UDP-4-keto-sugar.

Using purified Pgl enzymes from C. jejuni NCTC 11168, our lab has investigated the in vitro transfer of $\mathrm{N}, \mathrm{N}^{\prime}$-diacetylbacillosamine phosphate onto Und-P and the in vitro enzymatic synthesis of the heptasacccharide using a chemically synthesized undecaprenyl pyrophosphatelinked N,N'-diacetylbacillosamine (15,17). Starting from UDP-GalNAc, UDP-Glc, Und-P and chemically synthesized UDP-Bac-2,4-NAc, the reactions of PglC, PglA, PglH, PglJ and PglI have been coupled in a single reaction vessel to synthesize the bacterial glycan heptasaccharide (15). We wanted to confirm the presence of GST-PglF, PglE and PgID in the same reaction vessel did not inhibit the downstream reactions. In the absence of chemically synthesized UDPBac-2,4-NAc we combined the required substrates and cofactors for the reaction of each specific enzyme to proceed. The polyisoprene pyrophosphate-linked glycan was extracted from the organic phase and subsequently released from the polyisoprene by trifluoroacetic acid treatment and labeled with the fluorophore 2-aminobenzamide (2AB) at the $\mathrm{C} 1$ position of the diacetamido bacillosamine residue through reductive amination. HPLC analysis yielded a peak 
consistent with the known elution profile of the heptasaccharide and the identity of the eluted material was confirmed by MALDI-MS (Figure 8).

\section{DISCUSSION}

UDP-GlcNAc is modified by PglF to form the UDP-4-keto-sugar substrate of PglE in the prokaryotic glycoprotein $\mathrm{N}$-linked heptasaccharide biosynthesis pathway (18). In C. jejuni there are distinct metabolic pathways that share UDP-GlcNAc as a substrate, thus suggesting a rationale for the reaction kinetics observed in vitro. Pseudaminic acid, the major modification of flagellin, is synthesized via the UDP-GlcNAc dehydratase PseB pathway $(30,18)$. GalNAc, a major component in the biosynthesis of glycoprotein N-linked heptasaccharide, lipooligosaccharide (LOS), and capsule $(7,8,10)$, is synthesized intracellularly by the $\mathrm{C} 4$ epimerase Gne (31). Table 3 lists the kinetic parameters of PseB and Gne derived from other studies, as well as GST-PglF from this study. Clearly Gne is the most efficient of all three enzymes with a $\mathrm{k}_{\mathrm{cat}} / \mathrm{K}_{\mathrm{m}}$ greater than two orders of magnitude over the PseB and GST-PglF. This is to be expected since one or more copies of GalNAc/Gal or subsequent derivatives occur more frequently on cell surface structures (heptasaccharide, LOS, capsule) than GlcNAc/Glc related glycosides. The $\mathrm{k}_{\text {cat }} / \mathrm{K}_{\mathrm{m}}$ value of PseB indicates this enzyme is a moderately effective dehydratase, more so than GST-PglF by a factor of thirty. However, $p g l$ gene knockout studies on $C$. jejuni NCTC 11168 showed a significant disparity between wild-type and mutant strain signatures of the high resolution-magic angle spinning NMR spectra and whole-cell lysate blotting with lectins (32). These results indicate the substrate turnover rate of PseB is insufficient to complement the wild-type consumption levels of the UDP-4-keto-sugar by the Pgl pathway in the absence of PglF. Comparison of the kinetics data, together with the knockout study results support the hypothesis of a channeling mechanism where there exists a sequential transfer of products between enzymes of the same biosynthetic pathway (33). Of the two dehydratases compared, PseB has the lowest $\mathrm{K}_{\mathrm{m}}$, indicating a higher affinity for substrate. Studies on PseB knockouts in $C$. jejuni strain 81-176 showed the cells accumulated unglycosylated flagella intracellularly thus explaining a lack of motility (30). Arguably, when UDP-GlcNAc is in low abundance the pathogen would likely channel available stores toward the function of motility over host cell interactions.

Using a combination of radiolabel transfer, NMR, and ESI-MS we have shown that PgID catalyzes the acetyl group transfer from AcCoA to the UDP-4-amino-sugar, resulting in the formation of UDP-N,N'-diacetylbacillosamine (Figure 2). The proton NMR spectrum of UDPBac2,4diNAc shows a significant chemical shift of the $\mathrm{H} 4$ proton to a more deshielded position, consistent with the conversion of a primary amine at the $\mathrm{C} 4$ position of the pyranose ring to an amide (Figure 7). The $\mathrm{k}_{\mathrm{cat}} / \mathrm{K}_{\mathrm{m}}$ of PglD is $1.18 \times 10^{6} \mathrm{~min}^{-1} \mathrm{mM}^{-1}$, indicating the enzyme is very efficient in catalyzing the acetyl group transfer to the UDP-4-amino sugar. An advantage to such a high degree of activity results in the rapid consumption of the UDP-4-amino-sugar, thereby driving the enzymatic conversion of UDP-GlcNAc by PglF to UDP-4-keto-sugar; the substrate of PglE. Comparing kinetic data of the Pgl enzymes in Table 3 indicates the ratelimiting step in UDP-Bac2,4diNAc biosynthesis is the formation of the UDP-4-keto-sugar.

In vitro synthesis of $\mathrm{N}, \mathrm{N}^{\prime}$-diacetylbacillosamine and its precursors by enzymes of the $\mathrm{Pgl}$ pathway broadens the scope for potential applications. The $C$. jejuni oligosaccharyl transferase, $\mathrm{PglB}$, was shown to prefer a diacetylated sugar linked to the polysioprene pyrophosphate for glycosylation of peptides when the transferred sugar was a disaccharide (34). As the structure/ function relationship between Pgl enzymes and respective substrates become more defined, the potential to derive novel substrate analogues arises. Additionally, the capacity to synthesize milligram quantities of UDP-Bac2,4diNAc relatively inexpensively brings forth a new biologically relevant molecule that is suitable for modification by chemical means for probing biological processes. Because enzyme quantities were used in excess to ensure complete 
substrate turnover the in vitro reaction conditions may be optimized further to improve enzyme efficiency on a preparative scale. A more specific application is the use of purified UDPBac2,4diNAc to study protein modification pathways in other pathogens such as the Neisseria species, known to synthesize a diacetylated sugar for pilin glycosylation (35).

Successful coupling of reactions by PglE and GST-PglF suggests the involvement of the PglF transmembrane domain in preventing the inhibitory reaction observed between PglE and the soluble catalytic domain of PglF (18). Addition of the GST tag to the full-length PglF was critical to enhancing expression levels and simplifying the purification process. Reconstitution of heptasaccharide synthesis in vitro with full-length isolated proteins clearly demonstrates all eight $p g l$ enzymes are able to perform their respective functions in a single reaction vessel. Because substrate turnover was not observed in a reaction coupling GST-PglF 130 and PglE, we believe the presence of the GST tag fused to PglF was not responsible for disruption of inhibition in the coupled assay with full-length PglF and PglE. Experiments currently underway in our lab focus on the characterization of the presumed physical interaction between PglF and other enzymes of the Pgl pathway.

In summary, the evidence presented in this report identifies PglD as an acetyltransferase that catalyzes the last step in a three-step biosynthetic reaction of UDP-Bac2,4diNAc from UDPGlcNAc. This enzyme proved to be very efficient and may act as the engine that drives the metabolic conversion of UDP-GlcNAc to UDP-Bac2,4diNAc. The in vitro enzymatic synthesis of UDP-Bac2,4diNAc provides a straightforward method for producing milligram quantities of this material. In turn, this allows for a shift of attention towards investigating the mechanism of N-linked protein glycosylation and further the development of a bacterial protein glycosylation system for applications in biotechnology. We also report that as a GST fusion protein, the dehydratase PglF functioned in a coupled reaction with enzymes of the $p g l$ locus to synthesize the undecaprenylpyrophosphate heptasaccharide in vitro. This result suggests a greater role for the PglF transmembrane domain in the bacterial glycan biosynthesis other than to tether the catalytic domain of PglF to the lipid bilayer.

\section{Supplementary Material}

Refer to Web version on PubMed Central for supplementary material.

\section{Acknowledgements}

We thank M. Sainlos and L. Martin for assistance in obtaining MALDI-MS data, H. Pan and R. Kennedy for assistance in NMR data collection, in addition to K. Glover and B. Sculimbrene for critical reading of the manuscript.

This work was supported by the NIH: Grant GM039334 to B.I., GM075415 postdoctoral fellowship to N.B.O., and a HHMI predoctoral fellowship to J.R.B.

\section{ABBREVIATIONS}

$\mathbf{2 A B}$

2-aminobenzamide

$\operatorname{AcCoA}$

acetyl Coenzyme A

Bac2

4diNAc, 2,4-diacetamido-2,4,6-trideoxy- $\alpha$-D-glucopyranose (also called N,N'diacetylbacillosamine in this report)

BCA 
bicinchoninic acid

CE

capillary electrophoresis

\section{C. jejuni}

Campylobacter jejuni

\section{CoASH}

Coenzyme A

cv

column volume

Da

Daltons

E. coli

Escherichia coli

ESI

electrospray ionization

GS

glutathione Sepharose 4 Fast Flow resin

GST

glutathione S-transferase

IPTG

isopropyl_-D-1-thiogalactopyranoside

LB

Luria-Bertani

LOS

lipooligosaccharide

MALDI

matrix-assisted laser desorption/ionization

MWC

molecular weight cut-off

NAD $^{+}$

nicotinamide-adenine dinucleotide

NADP $^{+}$

nicotinamide-adenine dinucleotide phosphate

Ni-NTA

nickel-nitrilotriacetic acid

NMR

nuclear magnetic resonance

PAGE

polyacrylamide gel electrophoresis 
PBS

phosphate buffered saline

Pgl

protein glycosylation

PLP

pyridoxal-5'-phosphate

\section{P. aeruginosa}

Pseudomonas aeruginosa

RP-HPLC

reverse phase high performance liquid chromatography

SDS

sodium dodecyl sulfate

UDP

uridine-5'-diphosphate

\section{UDP-4-amino}

UDP-2-acetamido-4-amino-2,4,6-trideoxy- $\alpha$-D-glucopyranose

UDP-4-keto

UDP-2-acetamido-2,6-dideoxy- $\alpha$-D--xylo-4-hexulose

UDP-GIcNAc

UDP-2-acetamido- $\alpha$-D-glucopyranose

UDP-GalNAc

UDP-2-acetamido- $\alpha$-D-galactopyranose

Und-P

undecaprenyl phosphate

Glc

glucose

Gal

galactose

\section{References}

1. Altekruse SF, Stern NJ, Fields PI, Swerdlow DL. Campylobacter jejuni - an emerging foodborne pathogen. Emerg Infect Dis 1999;5:28-35. [PubMed: 10081669]

2. Butzler JP, Skirrow MB. Campylobacter enteritis. Clin Gastroenterol 1979;8:737-765. [PubMed: 387302]

3. Hughes RA, Hadden RD, Gregson NA, Smith KJ. Pathogenesis of Guillain-Barré syndrome. J Neuroimmunol 1999;100:74-97. [PubMed: 10695718]

4. Nita-Lazar M, Wacker M, Schegg B, Amber S, Aebi M. The N-X-S/T consensus sequence is required but not sufficient for bacterial N-linked protein glycosylation. Glycobiology 2005;15:361-367. [PubMed: 15574802]

5. Szymanski CM, Burr DH, Guerry P. Campylobacter protein glycosylation affects host cell interactions. Infect Immun 2002;70:2242-2244. [PubMed: 11895996] 
6. Wacker M, Linton D, Hitchen PG, Nita-Lazar M, Haslam SM, North SJ, Panico M, Morris HR, Dell A, Wren BW, Aebi M. N-linked glycosylation in Campylobacter jejuni and its functional transfer into E. coli. Science 2002;298:1790-1793. [PubMed: 12459590]

7. Linton D, Gilbert M, Hitchen PG, Dell A, Morris HR, Wakarchuk WW, Gregson NA, Wren BW. Phase variation of a $\beta-1,3$ galactosyltransferase involved in generation of the ganglioside Gm1-like lipooligosaccharide of Campylobacter jejuni. Mol Microbiol 2000;37:501-514. [PubMed: 10931344]

8. St Michael F, Szymanski CM, Li J, Chan KH, Khieu NH, Larocque S, Wakarchuk WW, Brisson JR, Monteiro MA. The structures of the lipooligosaccharide and capsule polysaccharide of Campylobacter jejuni genome sequenced strain NCTC 11168. Eur J Biochem 2002;269:5119-5136. [PubMed: 12392544]

9. Thibault P, Logan SM, Kelly JF, Brisson JR, Ewing CP, Trust TJ, Guerry P. Identification of the carbohydrate moieties and glycosylation motifs in Campylobacter jejuni flagellin. J Biol Chem 2001;276:34862-34870. [PubMed: 11461915]

10. Young NM, Brisson JR, Kelly J, Watson DC, Tessier L, Lanthier PH, Jarrell HC, Cadotte N, St Michael F, Aberg E, Szymanski CM. Structure of the N-linked glycan present on multiple glycoproteins in the Gram-negative bacterium, Campylobacter jejuni. J Biol Chem 2002;277:4253042539. [PubMed: 12186869]

11. Karlyshev AV, Ketley JM, Wren BW. The Campylobacter jejuni glycome. FEMS Microbiol Rev 2005;29:377-390. [PubMed: 15808749]

12. Szymanski CM, Logan SM, Linton D, Wren BW. Campylobacter - a tale of two protein glycosylation systems. Trends Microbiol 2003;11:233-238. [PubMed: 12781527]

13. Szymanski CM, Wren BW. Protein glycosylation in bacterial mucosal pathogens. Nat Rev Microbiol 2005;3:225-237. [PubMed: 15738950]

14. Linton D, Allan E, Karlyshev AV, Cronshaw AD, Wren BW. Identification of N-acetylgalactosaminecontaining glycoproteins Peb3 and CgpA in Campylobacter jejuni. Mol Microbiol 2002;43:497-508. [PubMed: 11985725]

15. Glover KJ, Weerapana E, Chen MM, Imperiali B. Direct biochemical evidence for the utilization of UDP-bacillosamine by PglC, an essential glycosyl-1-phosphate transferase in the Campylobacter jejuni N-linked glycosylation pathway. Biochemistry 2006;45:5343-5350. [PubMed: 16618123]

16. Linton D, Dorrell N, Hitchen PG, Amber S, Karlyshev AV, Morris HR, Dell A, Valvano MA, Aebi $\mathrm{M}$, Wren BW. Functional analysis of the Campylobacter jejuni N-linked protein glycosylation pathway. Mol Microbiol 2005;55:1695-1703. [PubMed: 15752194]

17. Glover KJ, Weerapana E, Imperiali B. In vitro assembly of the undecaprenylpyrophosphate-linked heptasaccharide for prokaryotic N-linked glycosylation. Proc Natl Acad Sci U S A 2005;102:1425514259. [PubMed: 16186480]

18. Schoenhofen IC, McNally DJ, Vinogradov E, Whitfield D, Young NM, Dick S, Wakarchuk WW, Brisson JR, Logan SM. Functional characterization of dehydratase/aminotransferase pairs from Helicobacter and Campylobacter: Enzymes distinguishing the pseudaminic acid and bacillosamine biosynthetic pathways. J Biol Chem 2006;281:723-732. [PubMed: 16286454]

19. Sharon N, Jeanloz RW. The diaminohexose component of a polysaccharide isolated from Bacillus subtilis. J Biol Chem 1960;235:1-5. [PubMed: 14445588]

20. Zehavi U, Sharon N. Structural studies of 4-acetamido-2-amino-2,4,6-trideoxy-D-glucose (Nacetylbacillosamine), the $\mathrm{N}$-acetyldiamino sugar of Bacillus licheniformis. J Biol Chem 1973;248:433-438. [PubMed: 4405424]

21. Allard ST, Beis K, Giraud MF, Hegeman AD, Gross JW, Wilmouth RC, Whitfield C, Graninger M, Messner P, Allen AG, Maskell DJ, Naismith JH. Toward a structural understanding of the dehydratase mechanism. Structure (Camb) 2002;10:81-92. [PubMed: 11796113]

22. Creuzenet C, Lam JS. Topological and functional characterization of wbpm, an inner membrane UDPGlcNAc C6 dehydratase essential for lipopolysaccharide biosynthesis in Pseudomonas aeruginosa. Mol Microbiol 2001;41:1295-1310. [PubMed: 11580835]

23. Dawson, RMC. Data for biochemical research. 3. Clarendon Press; Oxford: 1986.

24. Branch CL, Burton G, Moss SF. An expedient synthesis of allylic polyprenyl phosphates. Syn Commun 1999;29:2639-2644. 
25. Ye XY, Lo MC, Brunner L, Walker D, Kahne D, Walker S. Better substrates for bacterial transglycosylases. J Am Chem Soc 2001;123:3155-3156. [PubMed: 11457035]

26. Hallis TM, Lei Y, Que NL, Liu H. Mechanistic studies of the biosynthesis of paratose: Purification and characterization of CDP-paratose synthase. Biochemistry 1998;37:4935-4945. [PubMed: 9538012]

27. Beaman TW, Sugantino M, Roderick SL. Structure of the hexapeptide xenobiotic acetyltransferase from Pseudomonas aeruginosa. Biochemistry 1998;37:6689-6696. [PubMed: 9578552]

28. Magnet S, Lambert T, Courvalin P, Blanchard JS. Kinetic and mutagenic characterization of the chromosomally encoded Salmonella enterica aac $\left(6^{\prime}\right)$-iy aminoglycoside $\mathrm{N}$-acetyltransferase. Biochemistry 2001;40:3700-3709. [PubMed: 11297438]

29. Sweet CR, Ribeiro AA, Raetz CR. Oxidation and transamination of the 3"-position of UDP-Nacetylglucosamine by enzymes from Acidithiobacillus ferrooxidans. Role in the formation of lipid A molecules with four amide-linked acyl chains. J Biol Chem 2004;279:25400-25410. [PubMed: 15044494]

30. Goon S, Kelly JF, Logan SM, Ewing CP, Guerry P. Pseudaminic acid, the major modification on Campylobacter flagellin, is synthesized via the cj1293 gene. Mol Microbiol 2003;50:659-671. [PubMed: 14617187]

31. Bernatchez S, Szymanski CM, Ishiyama N, Li J, Jarrell HC, Lau PC, Berghuis AM, Young NM, Wakarchuk WW. A single bifunctional UDP-GlcNAc/Glc 4-epimerase supports the synthesis of three cell surface glycoconjugates in Campylobacter jejuni. J Biol Chem 2004;280:4792-4802. [PubMed: 15509570]

32. Kelly J, Jarrell H, Millar L, Tessier L, Fiori LM, Lau PC, Allan B, Szymanski CM. Biosynthesis of the N-linked glycan in Campylobacter jejuni and addition onto protein through block transfer. $\mathrm{J}$ Bacteriol 2006;188:2427-2434. [PubMed: 16547029]

33. Creuzenet C. Characterization of Cj1293, a new UDP-GlcNAc C6 dehydratase from Campylobacter jejuni. FEBS Lett 2004;559:136-140. [PubMed: 14960321]

34. Glover KJ, Weerapana E, Numao S, Imperiali B. Chemoenzymatic synthesis of glycopeptides with $\mathrm{PglB}$, a bacterial oligosaccharyl transferase from Campylobacter jejuni. Chem Biol 2005;12:13111315. [PubMed: 16356848]

35. Stimson E, Virji M, Makepeace K, Dell A, Morris HR, Payne G, Saunders JR, Jennings MP, Barker S, Panico M, et al. Meningococcal pilin: A glycoprotein substituted with digalactosyl 2,4diacetamido-2,4,6-trideoxyhexose. Mol Microbiol 1995;17:1201-1214. [PubMed: 8594338] 


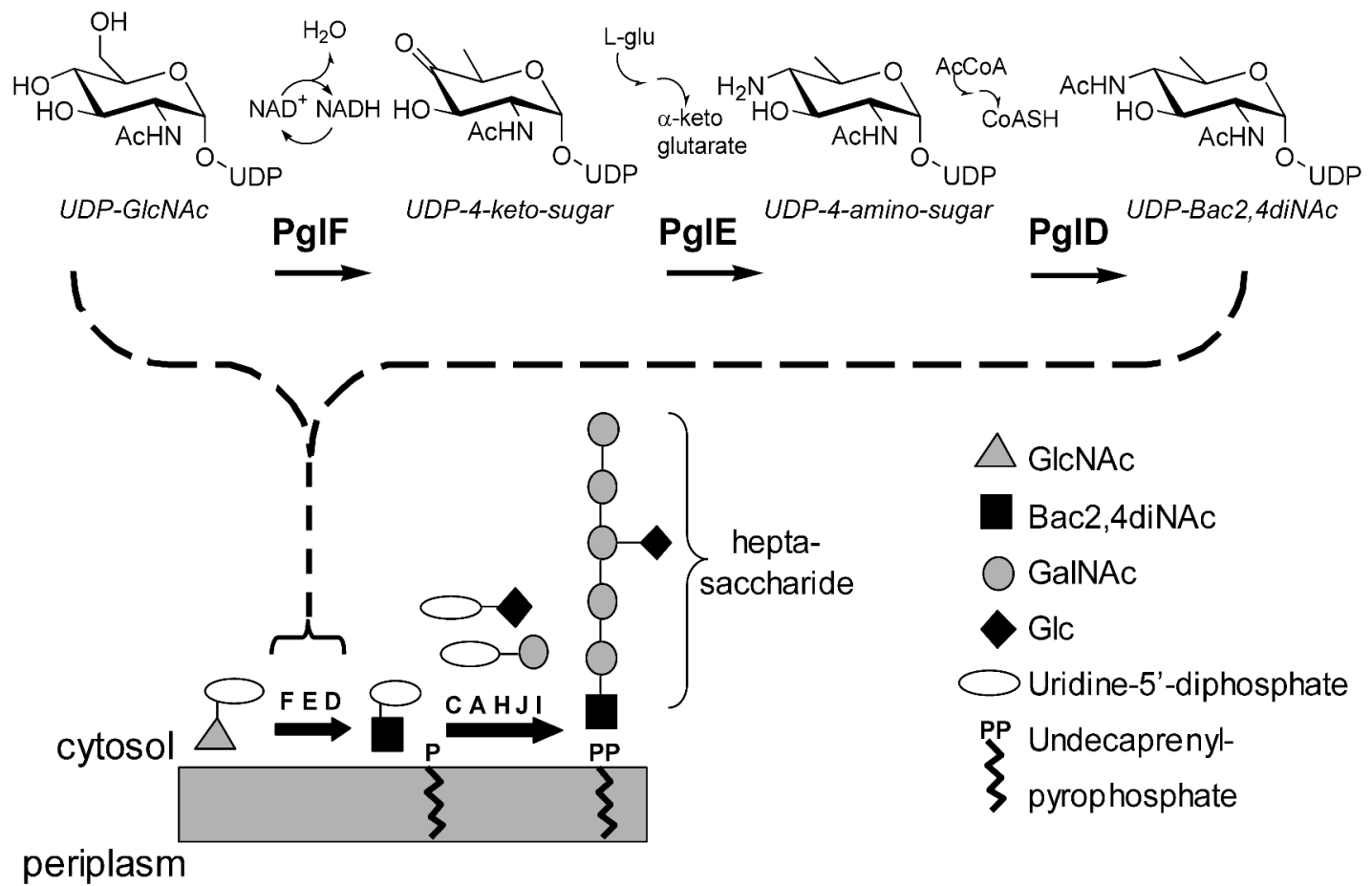

Figure 1.

Pathway of the enzymatic synthesis of the bacterial glycoprotein heptasaccharide from UDPGlcNAc by enzymes of the general protein glycosylation locus in $C$. jejuni. Enlarged is a detailed view of the pathway for UDP-Bac2,4diNAc synthesis. 


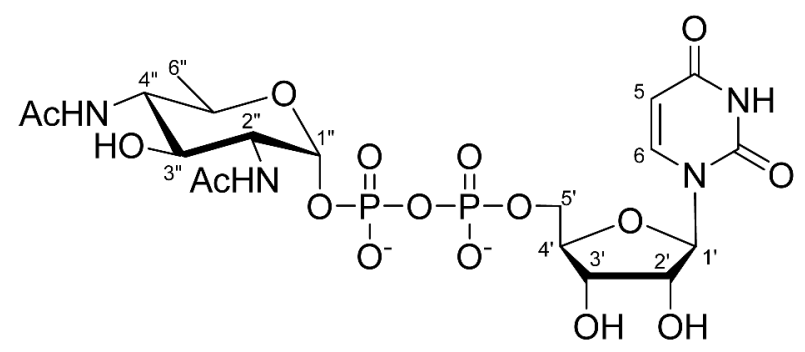

Figure 2.

Structure of UDP-2,4-diacetamido-2,4,6-trideoxy- $\alpha$-D-glycopyranose 


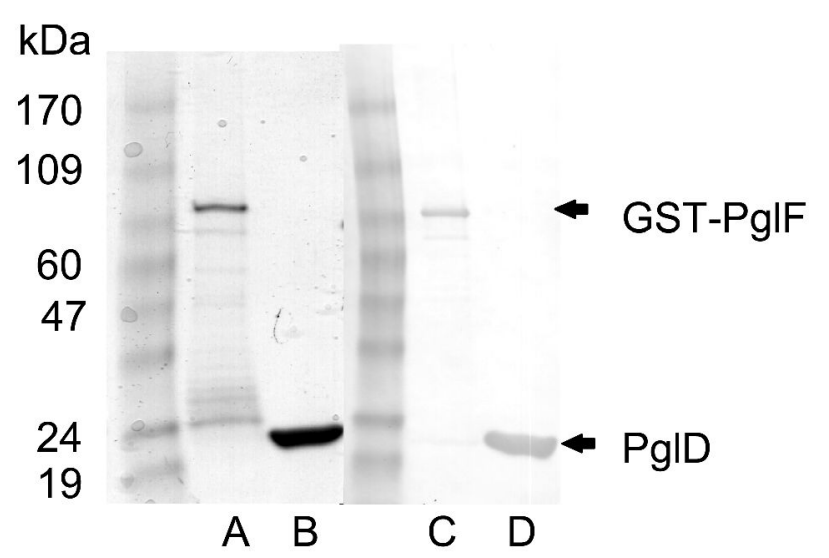

Figure 3.

(Lanes A \& B) Coomassie stained 4-15\% gradient SDS-PAGE gel of glutathione sepharose purified GST-PglF and Ni-NTA purified PglD. Calculated molecular mass for GST-PglF and PglD-His $_{6}$ are $93 \mathrm{k}$ Da and 23.5 k Da, respectively. (Lanes C \& D) Corresponding Western blot probing for C-terminal His-tag. Arrows indicate band representing the respective construct. 

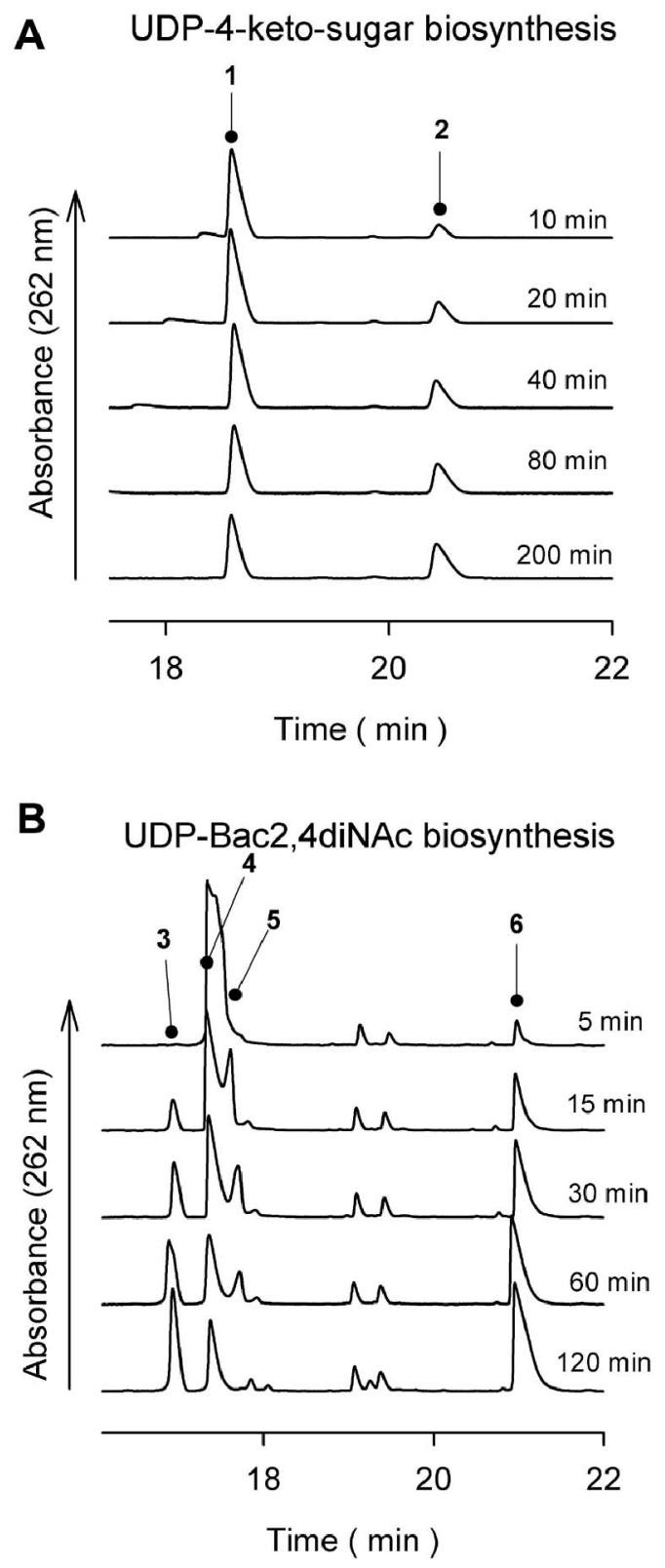

Figure 4.

CE Time-course analysis of (A) GST-PglF using $10 \_g$ enzyme with UDP-GlcNAc at $1 \mathrm{mM}$ final concentration and (B) PglD using $1.3 \mathrm{ng}$ of enzyme with UDP-4-amino and AcCoA at $1.2 \mathrm{mM}$ and $1.0 \mathrm{mM}$ final concentrations. Both reactions were conducted at $37^{\circ} \mathrm{C}, \mathrm{pH} 7.7$ with aliquots taken at the times indicated. Numbered peaks are 1, UDP-GlcNAc; 2, UDP-4-keto; 3, UDP-Bac; 4, UDP-4-amino; 5, AcCoA; 6, CoASH. 

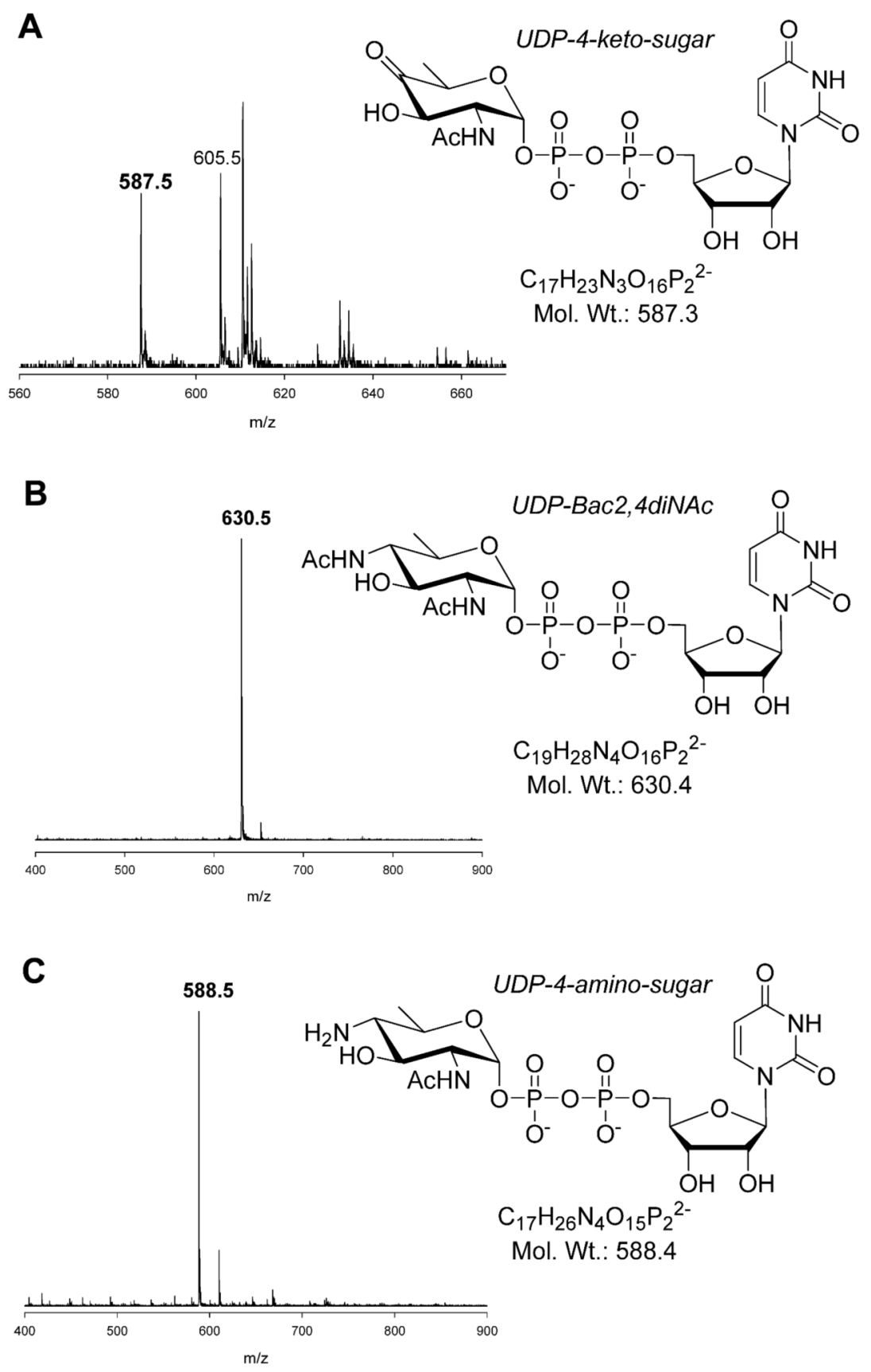

Figure 5.

ESI-MS of (A) GST-PglF reaction mixture. (B) HPLC purified UDP-Bac. (C) Ion exchange purification of UDP-4-amino from GST-PglF and PglE coupled reaction. 


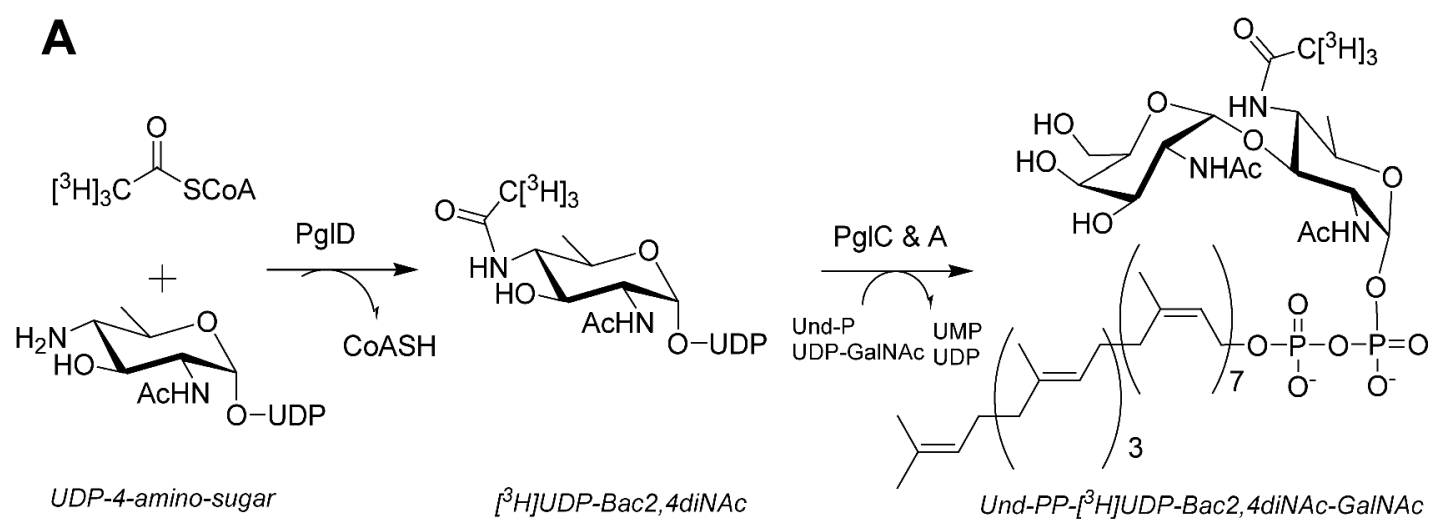

B

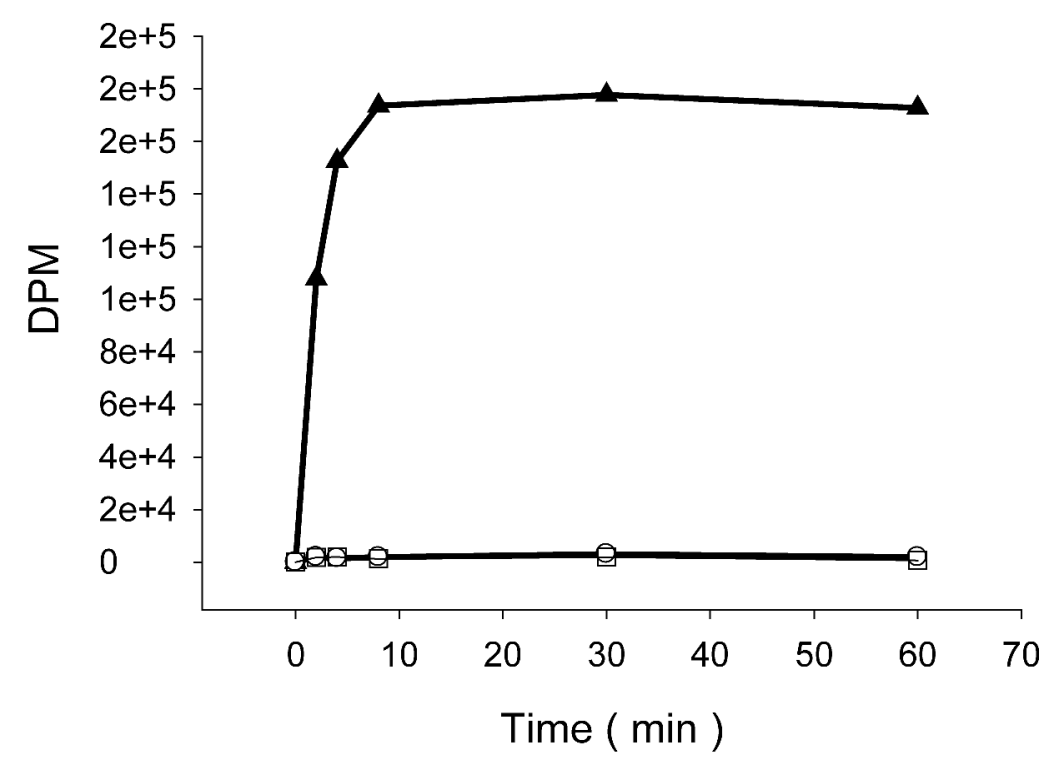

Figure 6.

(A) Reaction scheme for the transfer of ${ }^{3} \mathrm{H}$ labeled acetyl group to UDP-4-amino and onto Und-P by the enzymes PglD and PglC. PglA adds GalNAc to Und-PP- $\left[{ }^{3} \mathrm{H}\right] \mathrm{Bac}$. Aliquots of the reaction were taken over time and the organic phase subjected to liquid scintillation counting. (B) Plot of the liquid scintillation counts. Reactants included UDP-GalNAc $\left[{ }^{3} \mathrm{H}\right]$ AcCoA, Und-P, and UDP-4-amino ( $\boldsymbol{\Delta}$ ). Control reactions omitted Und-P (O) or UDP-4-amino (口). 
H-2'/R-3'

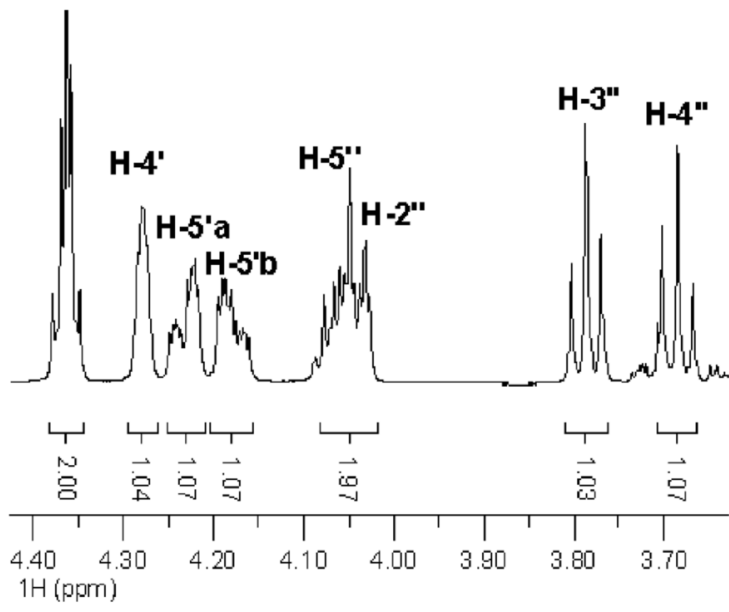

$2 \times \mathrm{NAC}-\mathrm{CH} 3$

H-1/H-5

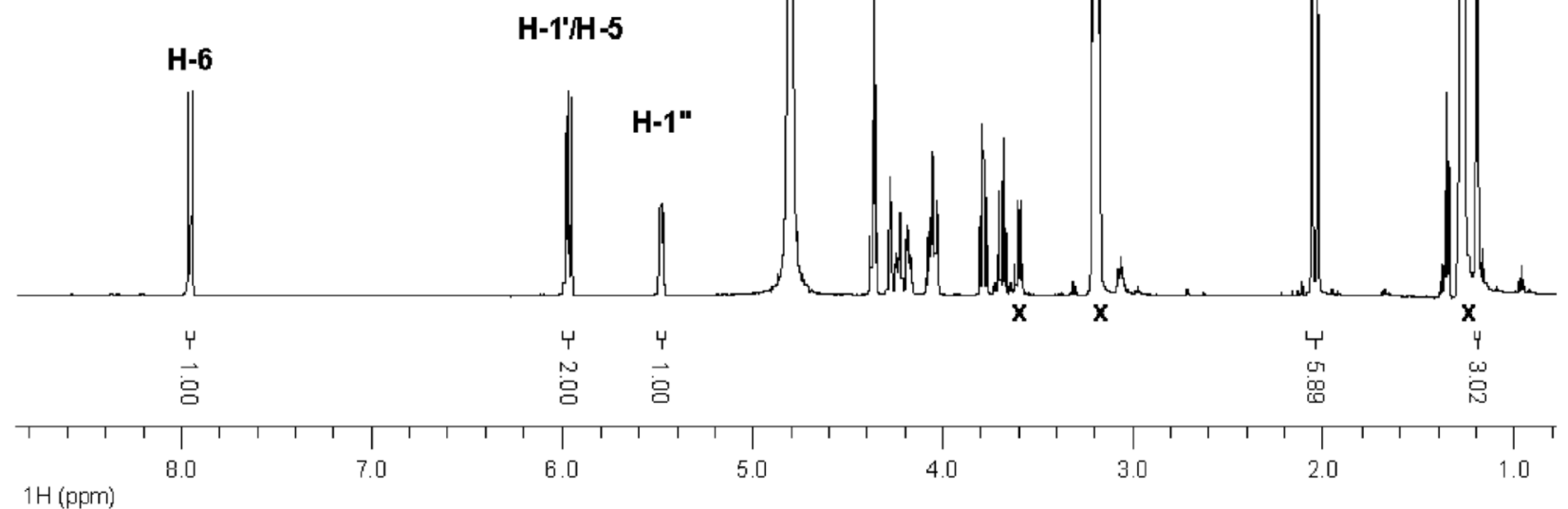

Figure 7.

${ }^{1} \mathrm{H}$ NMR spectrum of enzymatically synthesized UDP-Bac. Proton chemical shift labels follow the scheme represented in Figure 2 and values in Table 2. Peaks designated by ' $\mathbf{x}$ ' indicate signals from impurities and TEAB buffer. Peak surface and integration values are also indicated. Inset enlarges the view of proximally occurring chemical shifts from ribose and pyranose ring moieties. 


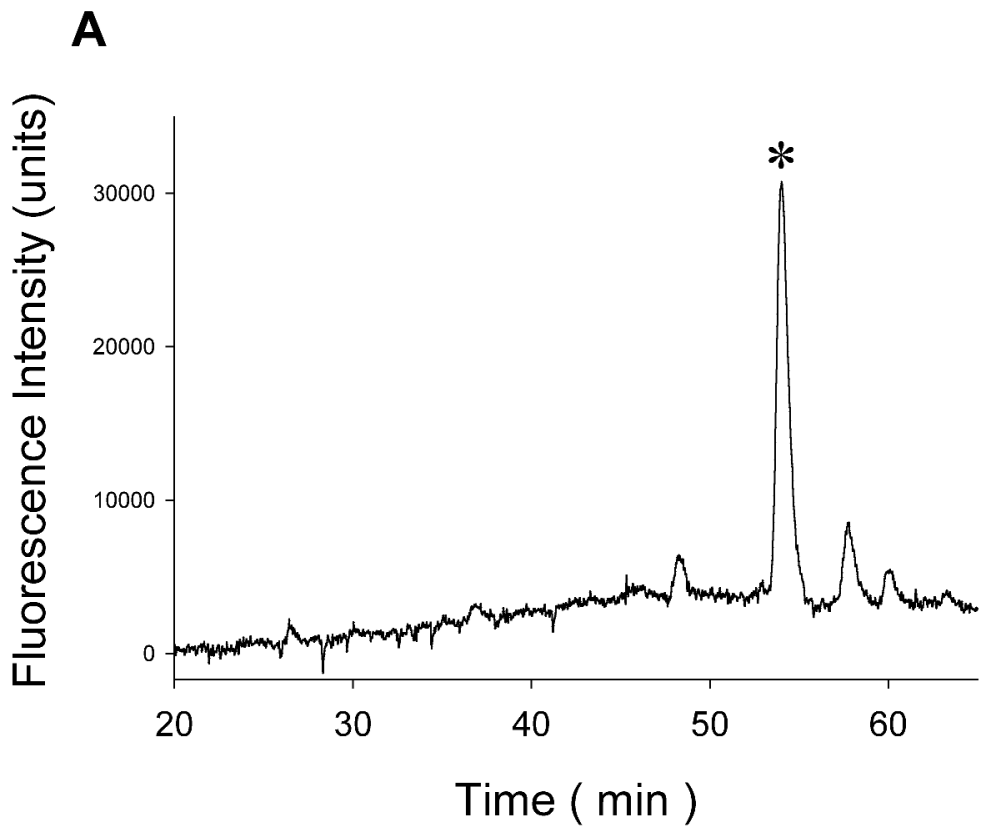

B

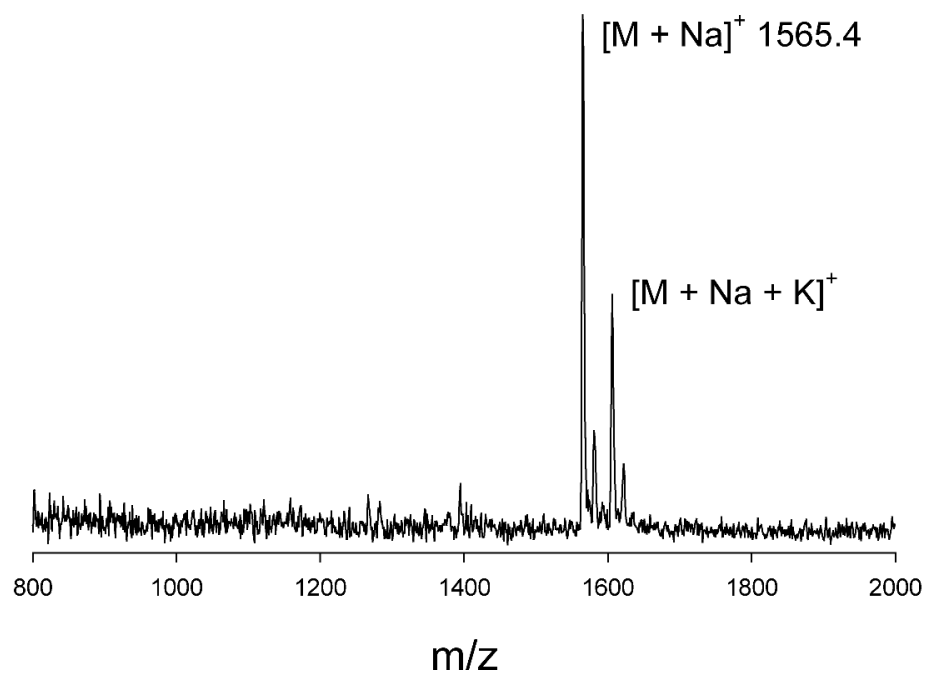

Figure 8.

(A) Fluorescence trace from HPLC analysis of 2AB-labeled heptasaccharide isolated from a reaction that coupled $\mathrm{PglF}, \mathrm{E}, \mathrm{D}, \mathrm{C}, \mathrm{A}, \mathrm{J}, \mathrm{H}$ and cell envelope fraction of $\mathrm{PgII}$ in one reaction vessel. '*' denotes the major saccharide peak. (B) MALDI-MS of eluted material. 
Table 1

Constructs and oligonucleotides used for this report

\begin{tabular}{|c|c|c|}
\hline Construct & Vector & $\operatorname{Primer}\left(5^{\prime}->3^{\prime}\right)$ \\
\hline GST-PglF & pGEX4T-2 & $\begin{array}{l}\text { Fwd: CGCGGATCCATGATTTTTTATAAAAGCAAAAGATTAGC } \\
\text { Rev: } \\
\text { CGGCTCGAGTCAGTGATGATGATGATGATGATGGTGTACACCTTCTTTATTGTGTTTAAATTC }\end{array}$ \\
\hline GST-PglF 130 & pGEX4T-2 & $\begin{array}{l}\text { Fwd: CGCGGATCCATGCTTGTGGATTTTAAACCTTC } \\
\text { Rev: } \\
\text { CGGCTCGAGTCAGTGATGATGATGATGATGATGGTGTACACCTTCTTTATTGTGTTTAAATTC }\end{array}$ \\
\hline PglE & pET24a $(+)$ & $\begin{array}{l}\text { Fwd: CGCGGATCCATGAGATTTTTTCTTTCTCC } \\
\text { Rev: CGGCTCGAGAGCCTTTATGCTCTTTAAG }\end{array}$ \\
\hline PglD & pET24a $(+)$ & $\begin{array}{l}\text { Fwd: CGCGGATCCATGGCAAGAACTGAAAAAATTTATATTTATGGTGC } \\
\text { Rev: CGGCTCGAGCATCCTTTTTGCAGGTAC }\end{array}$ \\
\hline
\end{tabular}


Table 2

${ }^{1} \mathrm{H}$ and ${ }^{31} \mathrm{P}$ NMR chemical shift and

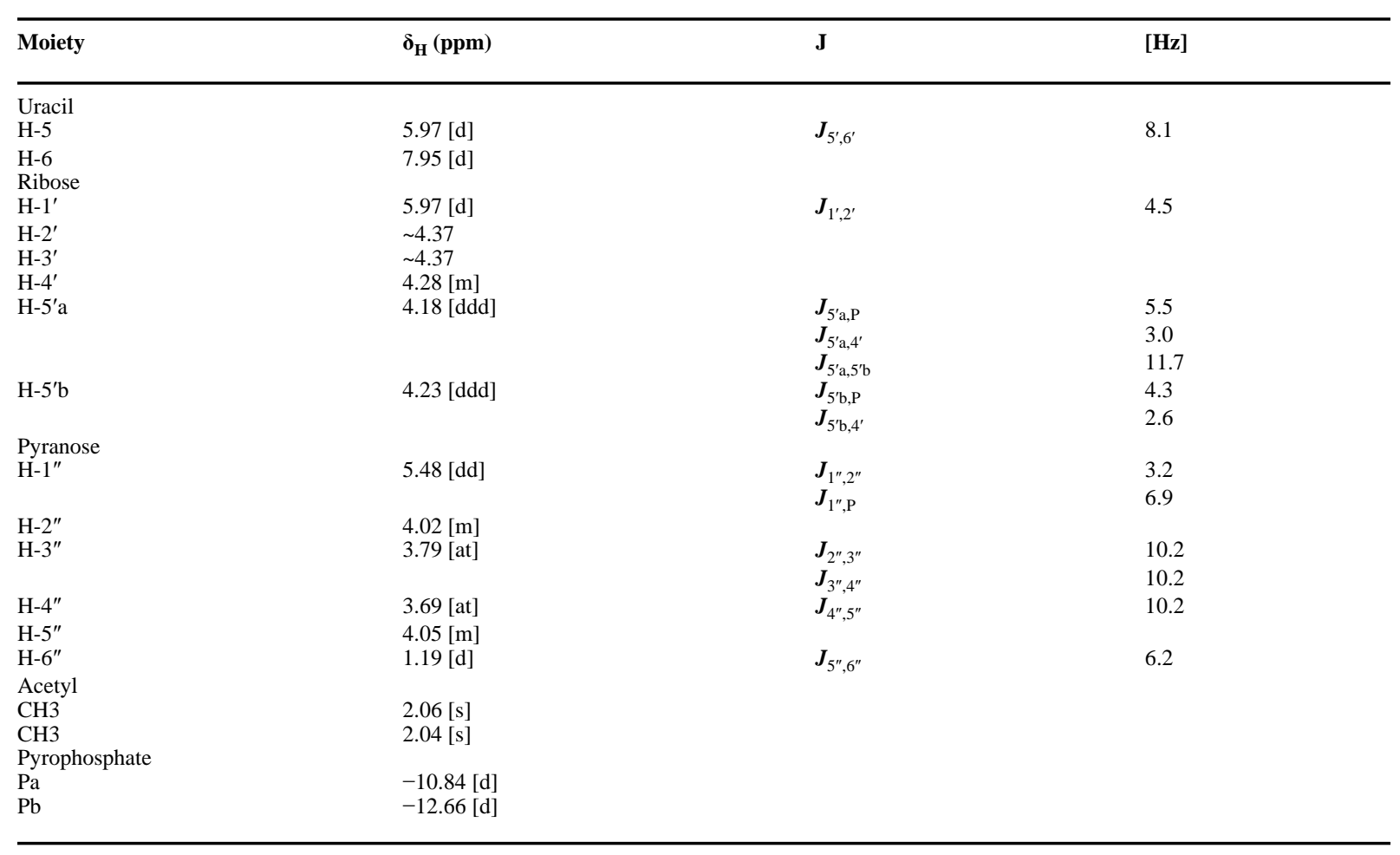

${ }^{a}$ Data collected at $25^{\circ} \mathrm{C}$ in $\mathrm{D}_{2} \mathrm{O}$, using $4.8 \mathrm{ppm}$ for the solvent chemical shift.

[d], doublet; [dd], doublet of doublets; [ddd], doublet of doublets of doublets [m], multiplet; [at], apparent triplet, [s] singlet. 


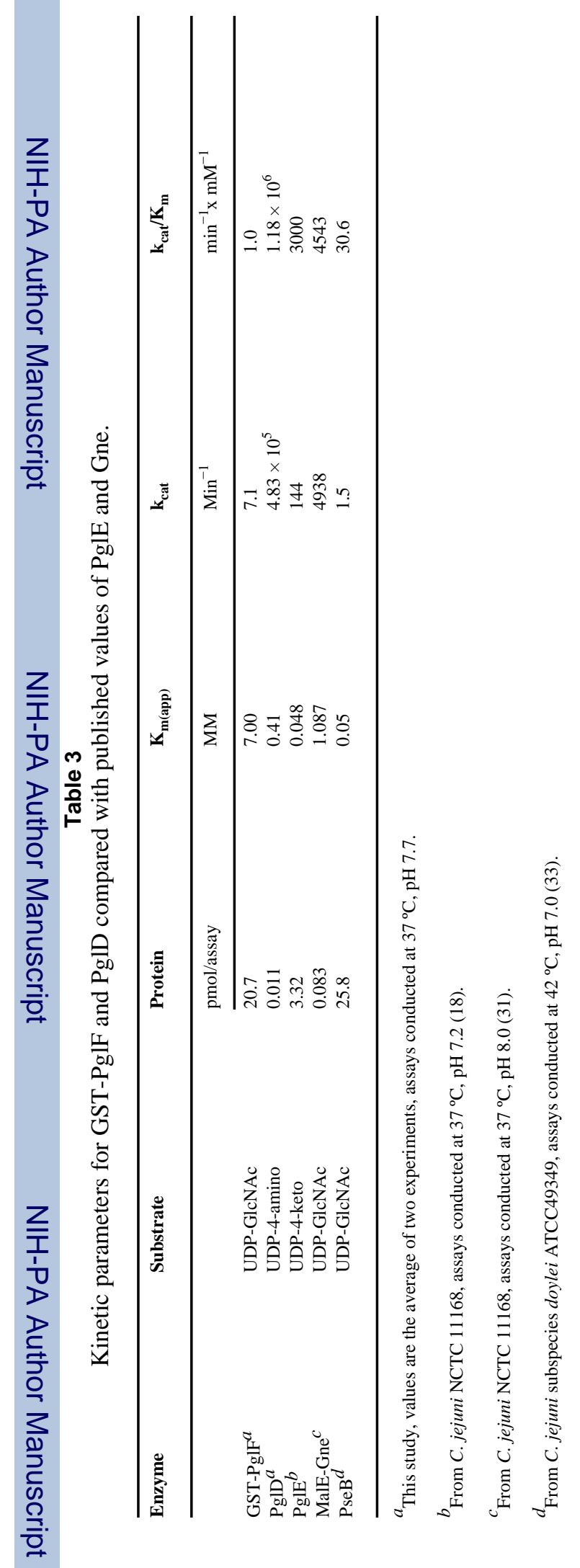

Biochemistry. Author manuscript; available in PMC 2008 September 18. 